\title{
The Use of a Vickers Indenter in Depth Sensing Indentation for Measuring Elastic Modulus and Vickers Hardness
}

\author{
Adonias Ribeiro Franco Jr., Giuseppe Pintaúde ${ }^{\mathrm{b}}$, Amilton Sinatora ${ }^{\mathrm{a}}$, \\ Carlos Eduardo Pinedo ${ }^{c}$, André Paulo Tschiptschin ${ }^{\text {a* }}$ \\ ${ }^{a}$ Dpto. de Eng. Metalúrgica e de Materiais and Dpto. de Eng. Mecânica, Escola Politécnica, \\ USP, Av. Prof. Mello Moraes, 2463, 05508-900 São Paulo - SP, Brazil \\ ${ }^{\mathrm{b}}$ Dpto. Acadêmico de Mecânica, Centro Federal de Educação Tecnológica do Paraná \\ Av. Sete de Setembro, 3165, 80230-901 Curitiba - PR, Brazil \\ ${ }^{\mathrm{c}}$ Núcleo de Pesquisas Tecnológicas, Universidade de Mogi das Cruzes \\ Av. Dr. Cândido Xavier de A. Souza 200, 08780-210 Mogi das Cruzes - SP, Brazil
}

Received: January 27, 2003; Revised: January 26, 2004

\begin{abstract}
Depth sensing indentation is a powerful experimental technique for determining mechanical properties of materials. In this work a computational routine was developed based on OliverPharr method for measuring a more precise values of elastic modulus using a Fischerscope H100 - depth sensing indentation apparatus, with a Vickers indenter. This computational routine aims also to measure Vickers hardness, as the equipment does not have software for this purpose. From indentation data it was possible to determine initial unloading stiffness, contact depth, projected contact area, reduced modulus, elastic modulus and Vickers hardness of materials. The validity of the routine was verified analyzing two coatings and nine bulk specimens with different elastic-plastic behaviors.

It was verified that the elastic moduli determined through the software of the equipment resulted in great discrepancies when low loads were applied. A good estimate of the elastic moduli of the tested materials is given by the developed routine. For several testing loads, the diagonals determined by means of analytical procedure were compared with the same diagonals measured by image analysis. A good estimate of the Vickers hardness of the above-mentioned materials is given by the developed routine using different testing loads.
\end{abstract}

Keywords: depth sensing indentation, elastic modulus, Vickers hardness, Oliver-Pharr method, ISE effect

\section{Introduction}

Load and displacement sensing indentation technique allows determining mechanical properties at penetration depths as low as $20 \mathrm{~nm}$, avoiding the substrate effect on the measurements ${ }^{1}$. The possibility to carry out tests in so small scales makes this technique one of the tools chosen to characterize mechanical properties of thin films, coatings, second phase particles and magnetic hard disk recording me$\operatorname{dia}^{2-4}$.

A well defined indenter geometry is required to get well defined indentation impressions. A perfect tip shape is difficult to achieve. Berkovich is a three-sided pyramid, and

*e-mail: aptschip@usp.br

Article presented at the XV CBECIMAT, Natal - RN, November/2002 provides a sharply pointed tip, compared to the Vickers indenter, which is a four-sided pyramid and has a slight offset $(0.5-\mu \mathrm{m})^{5,6}$. This is the main reason why three-sided Berkovich indenters are used in depth sensing indentation machines. However, any indenter with a sharp tip suffers from a finite but an exceptionally difficult to measure tip bluntness. Experimental procedures have been developed to correct the tip shape, of both Vickers and Berkovich indenters $^{1,7-10}$.

When tests are carried out with Berkovich indenters, the registered data can be analyzed using the method pro- 
posed in 1992 by Oliver and Pharr ${ }^{7}$, which has its origins in an earlier treatment by Doerner and $\mathrm{Nix}^{11}$. Nowadays, both methods are accepted for the analysis of the indentation data by the ISO/FDIS 14577-1 standard ${ }^{12}$. The Oliver-Pharr method consists in a series of loading cycles to avoid thermal drift and plastic reversion, while the Doerner-Nix method uses only a single cycle to obtain the indentation data. The Fischerscope H100 - depth sensing indentation machine uses the latter method, which is less time consuming and simpler but takes into account only a few data points, leading to greater inaccuracy. Moreover, the Fischerscope H100 uses the constant hardness calibration method ${ }^{8,13}$ to correct the indenter tip shape, which is not adequate since work-hardening may happen during the test.

The Oliver-Pharr method is widely used in depth sensing indentation machines with Berkovich indenter. However, it is equally applicable to the case depth sensing indentation using a Vickers indenter, with good results as mentioned in literature ${ }^{8,14,15}$. The depth sensing indentation machine used in this work analyzes indentation data using a software based on the Doerner-Nix method, and uses an incorrect area function to describe the indenter tip shape, leading to overestimated elastic modulus and hardness values due to ISE effect - indentation size effect ${ }^{16}$. Additionally, the Fischerscope apparatus software does not give Vickers numbers, which are useful to compare with wellknown data of phases and micro-constituents given in literature.

The present work aims to develop a computational routine based on the Oliver-Pharr method for measuring more precise values of elastic modulus and to obtain Vickers hardness numbers, using a Fischerscope H100 - depth sensing indentation apparatus, equipped with a Vickers diamond indenter.

\section{Theoretical Aspects}

Depth sensing indentation technique consists of printing an impression on the material surface by applying a known load with an indenter of known geometry and subsequently analyzing the load $v s$. displacement data. Equations from the elastic punch theory can be used to determine the elastic modulus, $E$, and hardness, $H$, provided that the following conditions during the initial withdrawal of the indenter are ensured:

- the material's recovery follows an elastic behavior;

- the contact area between the indenter and the specimen remains constant.

In this case, the Sneddon's solutions ${ }^{17,18}$ for the case of the indentation of an elastic half-space for a cylindrical punch approach to the elastic behavior. One of the Sneddon's solutions leads to a simple relation between the load, $P$, and the penetration depth, $h$, of the form:

$$
P=\frac{4 \mu a}{1-v} h
$$

where $a$ is the radius of the cylinder; $\mu$ is the shear modulus; and $v$ is Poisson's ratio. Knowing that the area of the contact circle projected onto the surface, $A_{c}$, is equal to $\pi a^{2}$ and that the shear modulus is related to the elastic modulus in the following way:

$$
E=2 \mu(1+v)
$$

and substituting (2) in (1) and differentiating the obtained expression with respect to $\mathrm{h}$ :

$$
\frac{d P}{d h}=\frac{2}{\pi} \sqrt{A c} \frac{E}{\left(1-v^{2}\right)}
$$

one can obtain the contact stiffness $S=d P / d h$. The elastic modulus, $E$, can be taken directly from the initial unloading slope, $S$, when Poisson' ratio, $v$, and contact area, $A_{c}$, are given. The latter can be measured independently as a function of contact depth, $h_{c}$.

As the elastic modulus of the indenter is not infinite, Eq. 3 should be written in terms of combined elastic modulus specimen/indenter $\left(E_{r}\right)$, which is, according to Hertz Equation:

$$
\frac{1}{E_{r}}=\frac{\left(1-v^{2}\right)}{E}+\frac{\left(1-v_{i}^{2}\right)}{E_{i}}
$$

where $E, E_{i}, v$ and $v_{i}$ are the elastic moduli and Poisson's ratios of the specimen and indenter, respectively.

Therefore, for the indentation of a plane surface of a semi-infinite elastic solid by a rigid punch, Eq. 3 can be rewritten:

$$
\frac{d P}{d h}=\frac{2}{\sqrt{\pi}} \sqrt{A c} E_{r} \text { or } E_{r}=\frac{\sqrt{\pi}}{2} \frac{S}{\sqrt{A_{C}}}
$$

The above Equation shows that, for axisymmetric indenters, the relationship between unloading stiffness, $S$, and contact area, $A_{c}$, does not depend upon indenter geometry. Pharr, Oliver, and Brotzen ${ }^{19}$ have shown experimentally that the analysis used for determining elastic moduli and contact areas from contact stiffness $S$ is not limited to punch geometry. Using finite elements method, King ${ }^{20}$ has introduced to Eq. 5 a correction factor for non-axisymmetric indenters:

$$
E_{r}=\beta \frac{\sqrt{\pi}}{2} \frac{S}{\sqrt{A_{C}}}
$$


where $\mathrm{b}$ corresponds to a correction factor related to the lack of symmetry of the indenter, which is equal to 1.0124 for Vickers indenters, and $A_{c}$ is the projected contact area.

Figures 1 to 3 show the main parameters used in analyzing indentation data.

In Figs 1 and $2, h_{\max }$ corresponds to the maximum depth, $a$ to the half-diagonal projected on the surface, $h_{f}$ to the residual depth, $h_{c}$ to the contact depth, and $h_{s}$ to the deflection depth. In Fig. 3, $S$ corresponds to the unloading stiffness for $h=h_{\max }$.

As the unloading from $h_{\max }$ to $h_{f}$ is elastic, one of the Sneddon's solutions ${ }^{8}$, for a conical punch (Figs. 1 and 2), shows that the deflection of the surface at the contact is:

$$
h_{s}=\left(\frac{\pi-2}{\pi}\right)\left(h-h_{f}\right)
$$

Another Sneddon's solution shows that, for $h=h_{\max }$, the load is related to the elastic depth:

$$
\left(h-h_{f}\right)=2 \frac{P}{S}
$$

Substituting (7) in (8) and noting that the contact area of interest is that at peak load, $P=P_{\max }$, it follows:

$$
h_{s}=\left[\frac{2(\pi-2)}{\pi}\right] \frac{P \max }{S} \quad \text { or } h_{s}=\varepsilon \frac{P \max }{d P / d h}
$$

To determine the contact depth from experimental data, one can note that in Fig. 1:

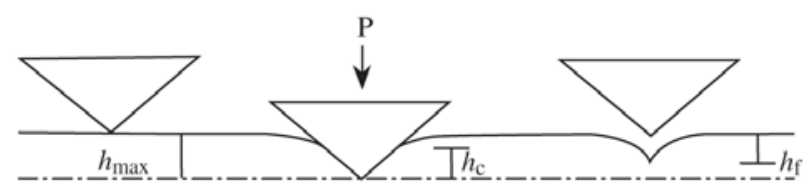

Figure 1. Profile of the surface before and after indentation.

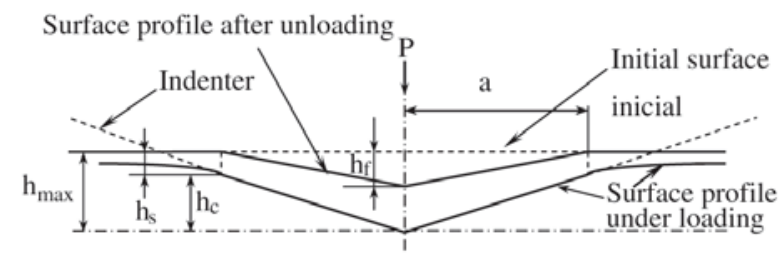

Figure 2. Main parameters used in analyzing unloading vs. indenter depth curves.

$$
h_{c}=h_{\max }-h_{s}
$$

Therefore:

$$
h_{c}=h_{\max }-\varepsilon \frac{P \max }{d P / d h}
$$

Considering that usually the indenters are not conical, but square or triangular base pyramids (Vickers or Berkovich indenters) it must take into account that for any revolution paraboloyd (including Vickers indenters), $\varepsilon$ is about $0.75^{19}$.

As one can see in Fig. $4 \mathrm{a}$, the contact area, $A_{c}$, can be expressed as a function of the diagonal $d^{21}$ :

$$
A_{c}=\frac{1}{2} d^{2}
$$

Substituting this expression in Eq. 6, one obtains the diagonal as a function of the indentation parameters:

$$
d=\beta \frac{S}{E_{r}} \sqrt{\frac{\pi}{2}}
$$

Eventually, the Vickers hardness numbers can be determined by the average diagonal, $d$, estimated from such parameters:

$$
A_{\text {Vicker } s}=\frac{d^{2}}{2 \cos 22^{\circ}}=\frac{d^{2}}{2 \operatorname{sen} \frac{136^{\circ}}{2}}=\frac{d^{2}}{1.854368}
$$

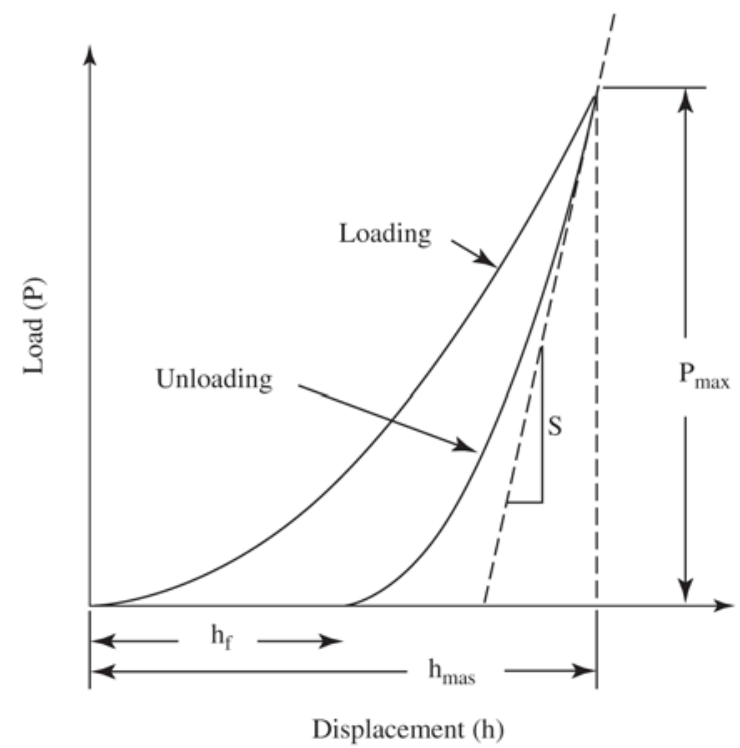

Figure 3. Schematic representation of load-displacement data for a depth sensing indentation experiment. 
Franco et al. Materials Research

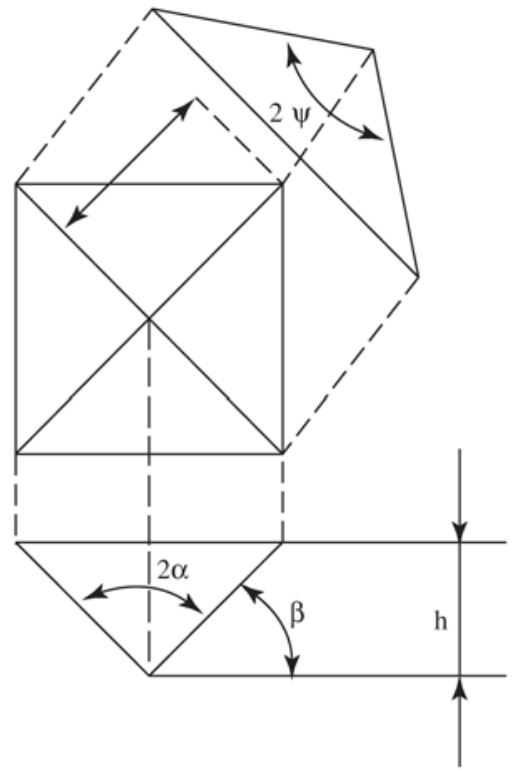

(a)

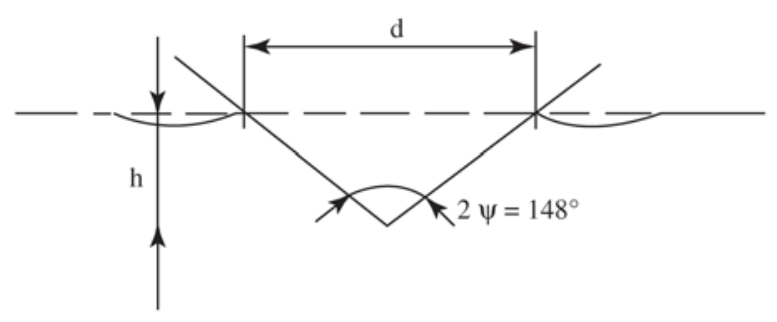

(b)

Figure 4. a) Vickers indenter: $A_{c}(d)=d^{2} / 2 ; \beta[\equiv(180-2 \alpha) / 2]=22^{\circ}$; and $d=2 a$. b) Under loading, the apex for Vickers indenter, $2 \Psi$, is equal to $148^{\circ}$.

$$
H_{V}=\frac{P}{A_{V i c \mathrm{ker} s}}
$$

\section{Experimental Details}

\subsection{Equipment and indentation procedure}

A Fischerscope H10O - depth sensing indentation machine equipped with a Vickers diamond indenter, manufactured by Helmut Fischer GmbH, was used. Such equipment allows applying loads from $1 \mathrm{mN}$ to $1000 \mathrm{mN}$ and registering penetration depths as a function of applied loads. Other important testing characteristics of the equipment are:

- control of loading and unloading rates $(d P / d t$ and $d \sqrt{ } P / d t)$;

- long or short delay times at maximum load;

- minimum step among indentations equal to $10 \mathrm{~mm}$;

- definition of the number and position of the indentations (mapping).
Table 1 shows the main testing conditions.

In all cases the indentation depth did not surpass $10 \%$ of the specimen thickness (film or substrate), avoiding any contribution from the substrate ${ }^{22}$.

\subsection{Materials}

The materials used in this study were chosen in order to include a wide range of hardness and elastic modulus values: PVD TiN and HVOF WC-12\%Co coatings, alumina, AISI D2 and AISI H13 tool steels, AISI 316 stainless steel, aluminum, gold, soda-lime glass, $\mathrm{Au}-12 \% \mathrm{Pt}$ and $\mathrm{Co}-25 \% \mathrm{Cr}$ odontological alloys. Table 2 presents elastic moduli for these materials reported in the literature.

Bulk specimens were mechanically polished and finished until $1 \mu \mathrm{m}$ diamond paste. The AISI H13 tool steel specimens coated with TiN and with WC - 12\% Co were carefully cleaned using an ultra-sound apparatus in alcohol bath and subsequently dried in warm air. The WC- $12 \%$ Co coating thickness is about $300 \mu \mathrm{m}$, while the TiN coating thickness is about $5 \mu \mathrm{m}$.

\subsection{Analytical procedure used by Fischerscope equip- ment}

Fischerscope procedure for measuring hardness and elastic modulus consists in estimating the initial slope from unloading data based on the Doerner-Nix analytical treatment and subsequently calculating the correct depth through a calibration curve, previously established for tip-shape indenter correction, frequently called hardness constant method $^{8,13}$.

Figure 5 shows the load-displacement data for alumina. Considering the unloading curve, the initial unloading slope, defined as contact stiffness, $d P / d h=S$, is determined taking the upper $1 / 3$ of the unloading data and fitting it by a linear relation of the form:

$$
P=S h+b
$$

where $b=-S h_{c}$.

A straight line is fitted to the unloading curve down to its first $1 / 3$ region and then extrapolated to zero, determining the depth $h_{s}$ and stiffness $S$.

Fitting the unloading data by a linear relation, yields $S=0.4719 \mathrm{mN} / \mathrm{nm}$ and $h_{s}=84 \mathrm{~nm}$. Because the Vickers indenter tip is not perfect, $h_{\max }$ is replaced by a corrected depth, $h_{c o r r}$, in a depth function of the form:

$$
h_{\text {corr }}=\sqrt{h^{2}\left(1+k h^{n}\right)}
$$

where $h_{\text {corr }}$ corresponds to equivalent depths from an ideal Vickers indenter, and $\mathrm{k}$ and $\mathrm{n}$ are empirical parameters. The surface area of the indenter is determined through the expression: 


$$
A=26.43 h_{\text {corr }}^{2}
$$

In the above expression, the factor 26.43 is used instead of 24.5 because the universal hardness $H_{u}$, taken for tip shape calibration, is based on surface area of an ideal Vickers indenter.

The surface area, $A$, together with the initial stiffness, $S$, is then substituted in Eq. 6, yielding a value of $325.4 \mathrm{GPa}$ for reduced modulus, $E_{r}$. Using Eq. 4 leads to $E=440 \mathrm{GPa}$ for alumina.

\subsection{Oliver-Pharr Analytical Procedure}

Referring to the unloading curve obtained experimentally for alumina (Fig. 5), one can note that it presents a non-linear behavior. Pharr, Oliver, and Brotzen ${ }^{19}$ showed that even metals present unloading curves with non-linear behavior and that these curves are better described by nonlinear relationships.

In the Oliver-Pharr method ${ }^{7}$, the data taken from the upper portion of the unloading curve (Fig. 5) are fitted by a power-law relation of the form:

$$
P=A\left(h-h_{f}\right)^{m}
$$

where $P$ is the indenter load, $m$ and $A$ are empirical constants determined after unloading data fitting, $h_{f}$ is the residual depth, and $h$ is the elastic displacement.

Although fittings corresponding to $80 \%$ of the unloading curve are recommended in the Oliver-Pharr method, the fitting used in the present work was only $52 \%$. When trying to fit more than $52 \%$ of the data of the unloading curve, it

Table 1. Indentation conditions.

\begin{tabular}{lr}
\hline Number of measurements & 20 \\
\hline Loading time, loading rate & $12 \mathrm{~s}, \mathrm{~d} \sqrt{\mathrm{P} / \mathrm{dt}}$ \\
Dwell time at maximum load (“creep”) & $20 \mathrm{~s}$ \\
Unloading time, unloading rate & $20 \mathrm{~s}, \mathrm{~d} \sqrt{\mathrm{P} / \mathrm{dt}}$ \\
\hline
\end{tabular}

Table 2. Elastic moduli reported in literature for the used materials.

\begin{tabular}{lcc}
\hline Material & Literature modulus (GPa) & Reference \\
\hline WC-12\%Co & 495 & 23 \\
$\mathrm{TiN}$ & $417(111)$ & 24 \\
$\mathrm{Al}_{2} \mathrm{O}_{3}(99.8 \%)$ & 375,393 & 25,26 \\
$\mathrm{Co}-25 \% \mathrm{Cr}$ & 211 & 27 \\
$\mathrm{H} 13$ tool steel & 210 & 28 \\
$\mathrm{D} 2$ tool steel & 207 & 28 \\
316 stainless steel & 192,195 & 29,30 \\
$\mathrm{Au}-12 \% \mathrm{Pt}$ & 77 & 31 \\
$\mathrm{Au}(99.98 \%)$ & 77 & 31 \\
Aluminum & 70,4 & 7 \\
Soda-lime glass & 69,9 & 7 \\
\hline
\end{tabular}

was verified that the contact stiffness, $S$, was underestimated. Probably, this effect is associated with the limitation of the Fischerscope equipment, which does not allow the inclusion of multiple cycles for minimizing the effects of thermal drift and plastic reversion.

Fitting the unloading data of Fig. 5 by a power law relation, it is obtained m equal to 1.386620 and $A$ equal to 0.053065 , as one can see in Fig. 6. Rearranging Eq. 19, the residual depth can be predicted:

$$
\left(\frac{P}{A}\right)^{1 / m}=h-h_{f} \Rightarrow h_{f}=h-\left(\frac{P}{A}\right)^{1 / m}
$$

When $P=P_{\max }=50 \mathrm{mN}$, the maximum penetration depth, $h=h_{\text {max }}$ is $270 \mathrm{~nm}$. Substituting the values of $\mathrm{m}, A, P$ and $h$ in Eq. 20, a value of $130 \mathrm{~nm}$ is obtained for $h_{f}$

The contact stiffness, $S$, is obtained by means of Eq. 19 differentiating $P$ with respect to $h$ :

$$
S=\frac{d P}{d h}=m A\left(h_{\max }-h_{f}\right)^{m-1}
$$

Substituting the values of $m$, A and $h_{f}$ in Eq. 21, the contact stiffness $S=0.4966 \mathrm{mN} / \mathrm{nm}$ is obtained.

The indenter-specimen contact depth, $h_{c}$, can be obtained using one of Sneddon's solutions given in Eq. 11. Substituting the values of $\varepsilon, P_{\max }$ and $S$ in the referred expression, a value of $195 \mathrm{~nm}$ is obtained for $h_{c}$.

The projected contact area, $A_{c}$, can be determined through the indenter area function, shown in Fig. 7.

This calibration curve for tip shape correction was previously established by means of an iterative procedure, called the constant elastic modulus method, described by OliverPharr ${ }^{7}$. Fine fittings of the empirical constants were performed using an alternative method ${ }^{32}$ consisting of comparing the indentation diagonals measured by image analysis with that predicted through Eq. 13.

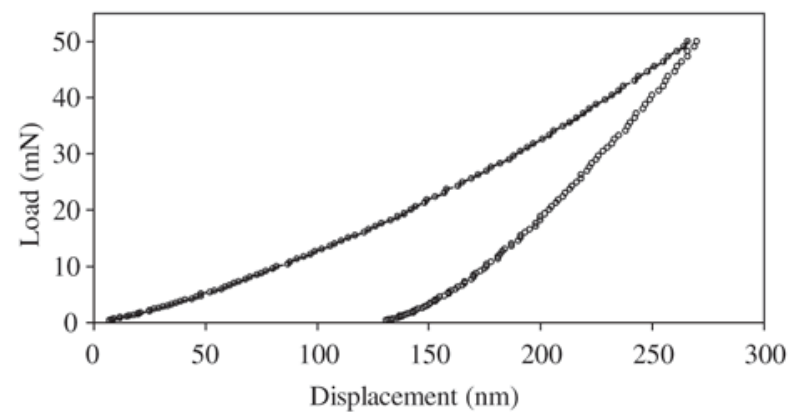

Figure 5. Load-displacement curve obtained experimentally for an alumina $\left(\mathrm{Al}_{2} \mathrm{O}_{3}\right)$ specimen. 
Then, substituting $h_{c}$ in the area function of the Vickers indenter:

$$
\text { Ac }=2.197912 \mu \mathrm{m}^{2}
$$

Then, after substituting this value together with that for contact stiffness in Eq. 6, a value of 293.2 GPa for reduced modulus $E_{r}$ is determined. Hence alumina modulus can be determined by using the Hertz expression (Eq. 4):

$$
E=380.3 \mathrm{GPa}
$$

\section{Discussion}

\subsection{Elastic Modulus}

Table 3 compares the results of elastic moduli measured using the developed computational routine with that

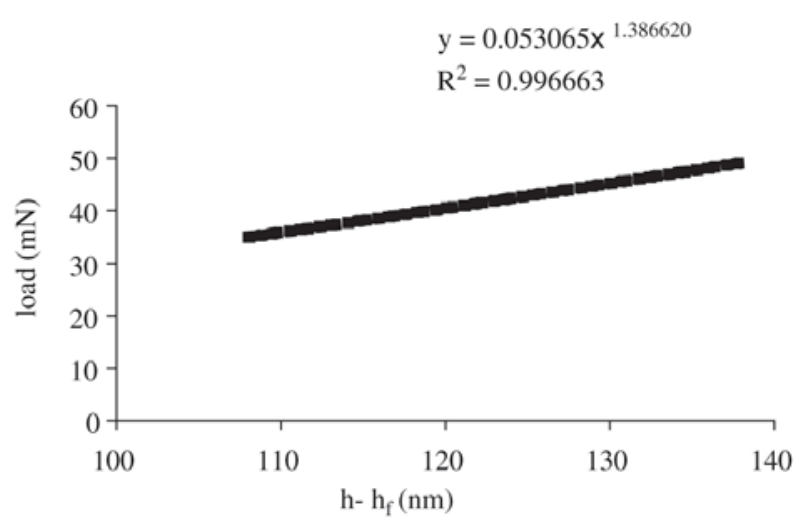

Figure 6. Unloading curve fitted by a power law relation of the form $\mathrm{P}=\mathrm{A}\left(\mathrm{h}-\mathrm{h}_{f}\right)^{\mathrm{m}}$.

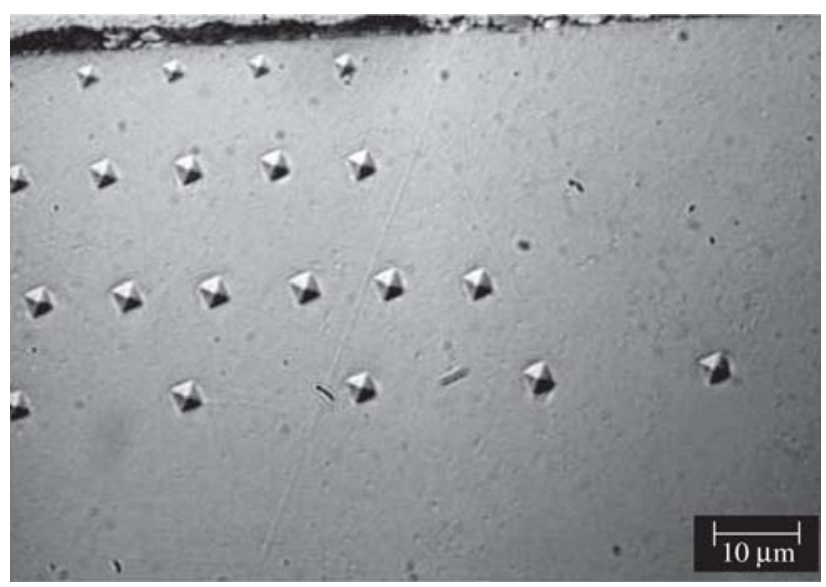

Figure 8. Vickers impressions taken beneath the nitrided layer of a $\mathrm{H} 13$ tool steel specimen. Load $=50 \mathrm{mN}$. yielded by the software of the equipment, together with values reported in the literature.

With respect to the values determined using the proposed routine, a good agreement is observed when compared with that reported in literature.

On the other hand, Table 3 shows that elastic moduli measured by the equipment are overestimated for materials with high elastic moduli. One can see in Table 3 that elastic moduli determined for alumina, through the Fischerscope routine, are greater overestimated the less is the applied load.

This effect is known as indentation size effect - "ISE effect" 16 , indicating that the analytical procedure used by the equipment introduces inaccuracies when low loads are applied. On the other hand, the proposed routine based on

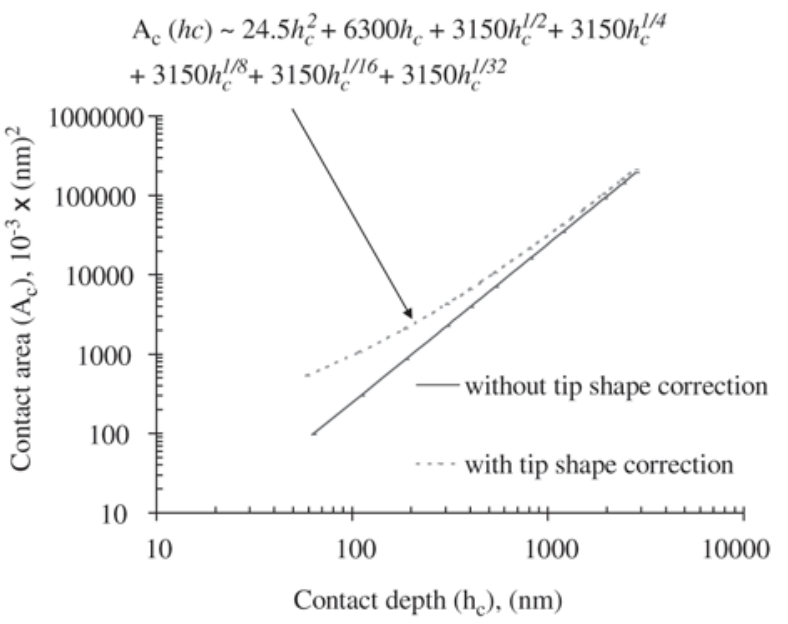

Figure 7. Area function, which takes into account roundness of the Vickers indenter tip, determined previously by the constant elastic modulus method and image analysis.

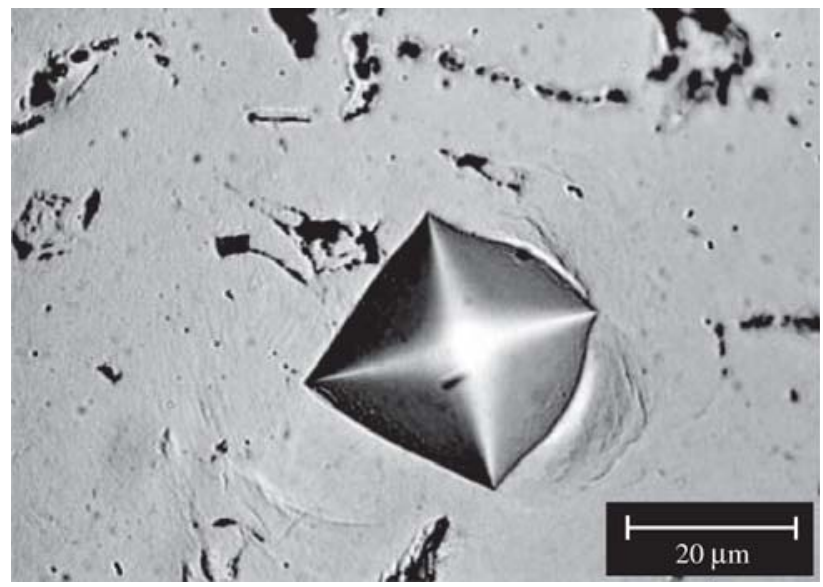

Figure 9. Vickers impression on top of aluminum. $\mathrm{Load}=255 \mathrm{mN}$. 
Table 3. Comparison of elastic moduli measured by means of the analysis procedure based on Oliver Pharr method with those given by Fischerscope machine. Each measurement corresponds to the average of twenty curves.

\begin{tabular}{|c|c|c|c|c|}
\hline Material & Load, $\mathrm{mN}$ & $\begin{array}{l}\text { Experimental modulus } \\
\text { (new routine), GPa }\end{array}$ & $\begin{array}{l}\text { Experimental modulus } \\
\text { (Fischer Software), GPa }\end{array}$ & $\begin{array}{c}\text { Literature } \\
\text { modulus, GPa }\end{array}$ \\
\hline \multirow[t]{2}{*}{ WC- $12 \% \mathrm{Co}$} & 50 & $477 \pm 49$ & $526 \pm 61$ & 490 \\
\hline & 100 & $481 \pm 42$ & $509 \pm 40$ & \\
\hline TiN & 30 & $411 \pm 20$ & $510 \pm 30$ & 417 (111) \\
\hline \multirow{3}{*}{$\mathrm{Al}_{2} \mathrm{O}_{3}(99.8 \%)$} & 50 & $380 \pm 18$ & $442 \pm 19$ & 375,393 \\
\hline & 500 & $378 \pm 06$ & $410 \pm 06$ & \\
\hline & 1000 & $379 \pm 05$ & $405 \pm 05$ & \\
\hline \multirow[t]{2}{*}{$\mathrm{Co}-25 \% \mathrm{Cr}$} & 100 & $209 \pm 10$ & $230 \pm 10$ & 211 \\
\hline & 500 & $208 \pm 10$ & $210 \pm 10$ & \\
\hline \multirow[t]{2}{*}{ H13 tool steel } & 50 & $208 \pm 07$ & $220 \pm 07$ & 210 \\
\hline & 500 & $207 \pm 07$ & $210 \pm 05$ & \\
\hline \multirow[t]{2}{*}{ D2 tool steel } & 100 & $206 \pm 07$ & $230 \pm 05$ & 207 \\
\hline & 700 & $207 \pm 05$ & $215 \pm 07$ & \\
\hline AISI 316 & 500 & $196 \pm 08$ & $182 \pm 08$ & 192,195 \\
\hline stainless steel & 750 & $197 \pm 06$ & $189 \pm 6$ & \\
\hline \multirow[t]{4}{*}{ Aluminum } & 40 & $70 \pm 02$ & $69 \pm 02$ & 70.4 \\
\hline & 80 & $69 \pm 02$ & $68 \pm 02$ & \\
\hline & 255 & $70 \pm 02$ & $68 \pm 02$ & \\
\hline & 750 & $69 \pm 03$ & $65 \pm 03$ & \\
\hline $\mathrm{Au}-12 \% \mathrm{Pt}$ & 100 & $81 \pm 04$ & $80 \pm 02$ & 77 \\
\hline $\mathrm{Au}(99.98 \%)$ & 10 & $77 \pm 06$ & $74 \pm 02$ & 77 \\
\hline \multirow[t]{5}{*}{ Soda-lime glass } & 5 & $68 \pm 02$ & $79 \pm 02$ & 69.9 \\
\hline & 10 & $69 \pm 01$ & $78 \pm 01$ & \\
\hline & 50 & $70 \pm 01$ & $80 \pm 01$ & \\
\hline & 500 & 70 & 80 & \\
\hline & 1000 & 71 & 80 & \\
\hline
\end{tabular}

the Oliver and Pharr method gives elastic moduli practical independent of the applied load, as one can see in Table 3.

\subsection{Vickers Hardness}

Figure 8 shows a set of measurements undertaken 5, 15, 25 and $35 \mu \mathrm{m}$ beneath the nitrided surface of a $\mathrm{H} 13$ tool steel specimen and Table 4 compares the diagonals measured by image analysis with those determined by means of Eq. 13, based on the calculated $S$ and $E_{r}$ values. It can be seen that the values given by both methods are very close.

Even in the case of large indentations (Fig. 9), the measured hardness values are in good agreement with those determined using Eq. 13, as can be seen in Table 5.

Finally, Table 6 shows the Vickers hardness numbers determined through the proposed routine for different materials presenting different elastic-plastic behaviors and in some cases obtained with different applied loads. The hardness values shown in Table 6 agree fairly well with the well-known Vickers hardness numbers of the different listed materials.

Therefore, artifacts in the measurements of the Vickers hardness owing to ISE effect alone can be ruled out. The new routine adapted to Fischerscope - depth sensing indentation apparatus allows measuring Vickers hardness of tribological coatings using very low loads without the necessity to derive expressions that relate coating hardness to substrate hardness, and to deal with the composite response of film and substrate.

\section{Conclusion}

- The proposed routine gives a better estimate of elastic moduli of materials, when compared to the values given by the equipment software.

- The lesser the load, the greater are the differences between the two methods.

- Very low loads can be used for determining elastic moduli of very thin layers, as the ISE effect was minimized.

- The elastic contact theory equations and the OliverPharr approach offer an optimum prediction of the indentation diagonals and, consequently, of the Vickers hardness numbers of the tested materials. 
Table 4. Indentation diagonals beneath the surface in a nitrided specimen, determined by means of Eq. 13 and measured by image analysis. Maximum load: $50 \mathrm{mN}$.

\begin{tabular}{ccc}
\hline $\begin{array}{c}\text { Distance from the nitrided surface } \\
(\mu \mathrm{m})\end{array}$ & $\begin{array}{c}\text { Average diagonal using Eq. 13 } \\
(\mu \mathrm{m})\end{array}$ & $\begin{array}{c}\text { Average diagonal, using Image analysis } \\
(\mu \mathrm{m})\end{array}$ \\
\hline$\sim 5$ & $3.19 \pm 0.07$ & $3.20 \pm 0.1$ \\
$\sim 15$ & $3.80 \pm 0.08$ & $3.81 \pm 0.1$ \\
$\sim 25$ & $4.02 \pm 0.06$ & $4.00 \pm 0.2$ \\
$\sim 35$ & $4.04 \pm 0.07$ & $4.03 \pm 0.2$ \\
\hline
\end{tabular}

Table 5. Comparison of Vickers hardness number determined using Eq. 11 with that measured by image analysis for an aluminum specimen. Load $=255 \mathrm{mN}$.

\begin{tabular}{lcc}
\hline $\begin{array}{c}\text { Average diagonal, } \mathrm{d} \\
(\mu \mathrm{m})\end{array}$ & $\begin{array}{c}\text { Area, } \mathrm{A}_{\text {vickers }} \\
\left(\mu \mathrm{m}^{2}\right)\end{array}$ & $\begin{array}{c}\text { Vickers number, } \mathrm{H}_{\mathrm{v}} \\
\left(\mathrm{kgf} / \mathrm{mm}^{2}\right)\end{array}$ \\
\hline 35.14 (Eq. 13) & 665.96 & 38 \\
34.65 (Image analysis) & 647.46 & 39 \\
\hline
\end{tabular}

Table 6. Hardness Vickers determined experimentally using different loading, for materials of different elastic-plastic behaviors.

\begin{tabular}{ccc}
\hline Material & $\begin{array}{c}\text { Hardness Vickers, } \\
\mathrm{kgf} / \mathrm{mm}^{2}\end{array}$ & $\begin{array}{c}\text { Load, } \\
\mathrm{mN}\end{array}$ \\
\hline $5.0 \mu \mathrm{m}$ TiN coating & $2421 \pm 119$ & 30 \\
$\mathrm{Al}_{2} \mathrm{O}_{3}(99.8 \%)$ & $2005 \pm 50$ & 1000 \\
& $1947 \pm 81$ & 500 \\
& $2028 \pm 135$ & 50 \\
$300 \mu \mathrm{m}$ WC-12\%Co coating & $1399 \pm 167$ & 50 \\
& $1455 \pm 90$ & 100 \\
AISI D2 tool steel & $650 \pm 59$ & 250 \\
Soda-lime glass & $550 \pm 02$ & 50 \\
AISI H13 tool steel & $485 \pm 17$ & 50 \\
& $481 \pm 9$ & 500 \\
Co-25\%Cr & $398 \pm 35$ & 100 \\
& $403 \pm 35$ & 500 \\
316 stainless steel & $228 \pm 7$ & 750 \\
Au (99.98\%) & $217 \pm 11$ & 10 \\
Au-12\%Pt & $194 \pm 14$ & 100 \\
Aluminum & $35 \pm 4$ & 750 \\
\hline
\end{tabular}

\section{Acknowledgments}

The financial support of the FAPESP, Fundação de Amparo à Pesquisa do Estado de São Paulo, is gratefully acknowledged.

\section{References}

1. Pethica, J.B.; Hutchings, R.; Oliver, W.C. Hardness measurement at penetration depths as small as $20 \mathrm{~nm}$. Philo- sophical Magazine A, v. 48, n. 4, p. 593-606, 1983.

2. Pharr, G.M. Measurement of mechanical properties by ultra-low load. Materials Science and Engineering A, v. 253, n. 1-2, p. 151-159, 1998.

3. Carvalho, S.; Vaz F.; Rebouta, L.; Schneider, D.; Cavaleiro, A.; Alves, E. Elastic properties of (Ti,Al,Si)N nanocomposite films. Surface and Coatings Technology, v. 142-144, p. 110-116, 2001.

4. Lo, R.Y; Bogy, D.B. Compensating for elastic deformation of the indenter in hardness tests of very hard materials. Journal of Materials Research, v. 14, n. 6, p. 227622, 1998.

5. Bhushan, B.; Gupta, B.K. Macro and Micro mechanical and tribological properties. In: Handbbok of Hard Coatings - Deposition Technologies, Properties and Applications. Bunshah, R.F. Ed. - Noyes Publications, Park Ridge, New Jersey, USA, p. 550, 2001.

6. Trindade, A.C.; Cavaleiro, A.; Fernandes, J.V. Estimation of Young's modulus and of hardness by ultra-low load hardness tests with a Vickers indenter. Journal of Testing and Evaluation, v. 22, n. 4, p. 365-369, 1994.

7. Oliver, W.C.; Pharr, G.M. A new improved technique for determining hardness and elastic modulus using load and sensing indentation experiments. Journal of Materials Research, v. 7, n. 6, p. 1564-1582, 1992.

8. Seitzman, L.E. Mechanical properties from instrumented indentation: uncertainties due to tip-shape correction. Journal of Materials Research, v. 13, n. 10, p. 29362944, 1998.

9. Herrmann, K.; Jennett, N.M.; Wegener, W., Meneve, J., Hasche, K.; Seemann, R. Progress in determination of the area function of indenters used for nanoindentation. Thin Solids Films, v. 377-378, p. 394-400, 2000.

10. Thurn, J.; Cook, F. Simplified function for sharp indenter tips in depth-sensing indentation. Journal of Materials Research, v. 17, n. 5, p. 1143-1146, 2002.

11. Doerner, M.F.; Nix, W.D. A method for interpreting the data depth-sensing indentation instruments. Journal of Materials Research, v. 1, n. 4, p. 601-609, 1986.

12. ISO/FDIS 14577-1. Metallic materials - Instrumented indentation test for hardness and material parameter, Part 1: Test method. ISO - International Organization 
for Standardization, Geneve, Switzerland, 2002.

13. Weiler, W.W. Dynamic loading - a new microhardness test method. Journal of Testing and Evaluation, v. 18, n. 4, p. 229-239, 1990.

14. Atar, E.; Cimenoglu, H.; Kayali E.S. Hardness characterisation of thin $\mathrm{Zr}$ (Hf,N) coatings. Surface and Coatings Technology, v. 162, n. 2-3, p. 167-173, 2003.

15. Strange D.J; Varshneya, A.K. Finite element simulation of microindentation on aluminum. Journal of $M a-$ terials Science, v. 36, p. 1943-1949.

16. Iost, A.; Bigot, R. Indentation size effect: Reality or artefact?. Journal of Materials Science, v. 31, n. 13, p. 3573-3577, 1996.

17. Harding, J.W.; Sneddon, I.N. The elastic stresses produced by the indentation of the plane surface of a semiinfinite elastic solid by a rigid punch. In: Proc. Cambridge Philos. Soc., v. 41, p. 16-26, 1945.

18. Sneddon, I.N. The relation between load and penetration in the axisymmetric Boussinesq' problem for a punch of arbitrary profile. International Journal of Science Engineering, v. 3, p. 47-57, 1965.

19. Pharr, G.M.; Oliver, W.C.; Brotzen, F.R. On the generality of the relationship among contact stiffness, contact area, and elastic modulus during indentation. Journal of Materials Research, v. 7, n. 3, p. 613-617, 1992.

20. King, R.B. Elastic analysis of some punch problems for a layered medium. International Journal of Solids Structures, v. 23, n. 12, p. 1657-1664, 1987.

21. Loubet, J.L.; Georges, J.M.; Marchesini, O.; Meillee, G. Vickers indentation curves of magnesium oxide (MgO). Journal of Tribology, v. 106, p. 43-48, 1984.

22. Johnson, K.L. The correlation of indentation experiments. Journal of Mechanics and Physics of Solids, v. 18, p. $115-126,1970$.

23. Chawla, N.; Patel, B.V.; Koopman, M.; Chawla K.K., Saha R., Patterson B.R., Fuller E.R., Langer S.A. Micro structure-based simulation of thermomechanical behavior of composite materials by object-oriented finite element analysis. Materials Characterization, v. 49, n. 5, p. 395-407, 2002.

24. Zhang, M.; He, J. Ab-initio calculation of elastic constants of TiN. Surface and Coatings Technology, v.142, p.125-131, 2001.

25. Zeng, K.; Söderlund, E.; Giannakopoulos, E.A.; Rowcliffe, D.J. Controlled indentation: a general approach to determine mechanical properties of brittle materials. Acta Materialia, v. 44, n. 1, p. 1127-1141, 1996.

26. Giannakopoulos, E.A.; Larsson, P-L. Analysis of pyramid indentation of pressure-sensitive hard metals and ceramics. Mechanics of Materials, v. 25, p. 1-35, 1997.

27. Morris, H.F. Properties of cobalt-chromium metal ceramic alloys after heat treatment. J. Prosthet. Dent., v. 62, p. 426-433, 1989.

28. Antunes, J.M.; Cavaleiro, A.; Menezes, L.F.; Simões, M.I.; Fernandes J.V. Ultra-microhardness testing procedure with Vickers indenter. Surface and Coatings Technology, v. 149, n. 1, p. 27-35, 2002.

29. Tran, M.D.; Poublan J.; Dautzenberg, J.H. A practical method for the determination of the Young's modulus and residual stresses of PVD thin films. Thin Solids Films, v. 308-309, p. 310-314, 1997.

30. Leyland, A.; Matthews, A. On the significance of the $\mathrm{H} / \mathrm{E}$ ratio in wear control: a nanocomposite coating approach to optimised tribological behaviour. Wear, v. 246, p. 1-11, 2000.

31. Craig, R.G.; Peyton, F.A.; Johnson, D.W. Compressive properties of enamel, dental cements and gold. J. Dent. Res., v. 40, n. 5, p.936-945, 1961.

32. Franco Jr., A.R. Obtenção de revestimentos dúplex por nitretação a plasma e PVD-TiN em aços ferramenta AISI H13 e AISI D2. Tese de doutorado, p. 178, EPUSP, São Paulo, SP, 2003. 